\title{
FORMAÇÃO DO ENFERMEIRO AEROESPACIAL: UM ESTUDO DESCRITIVO
}

Reila Campos Guimarães de ARAÚJO'1; Pablo Randel Rodrigues GOMES²; Cácia Régia de PAULA ${ }^{3}$; Alberto César da Silva LOPES ${ }^{4}$

\section{RESUMO}

Introdução: Este estudo aborda a formação do enfermeiro aeroespacial e o serviço de resgate aéreo brasileiro. Objetivo: descrever a formação do enfermeiro aeroespacial a partir dos pontos de vista da legislação vigente e de estudos sobre serviço aeromédico. Método: trata-se de um estudo reflexivo, de abordagem descritiva. A construção do estudo compreendeu a leitura de artigos, alguns trabalhos de conclusão de curso, legislação vigente e a discussão teórica a partir da pergunta norteadora: Qual a formação dos enfermeiros que atuam no apoio aeromédico? Resultados e discussões: a partir da análise descritiva e crítica de sete publicações, obtidas por meio de busca assistemática na literatura, e discussões entre os autores construiu-se duas categorias de discussão: "Serviço de Resgate Aeromédico"; "Formação do Enfermeiro Aeroespacial". Considerações finais: o Enfermeiro Aeroespacial necessita obter formação que subsidie a prestação de assistência de qualidade, de forma ágil, garantindo a segurança do paciente e da equipe no processo de resgate Aeromédico.

Palavras-chave: Resgate Aéreo. Educação em Enfermagem. Transporte de Pacientes.

\section{INTRODUÇÃO}

O atendimento móvel para vítimas surgiu pela primeira vez durante as primeiras Guerras Mundiais, onde os combatentes feridos eram retirados do campo de batalha pelos soldados companheiros de guerra, em carroças puxadas por cavalos. Apropriarse dessa historicidade permite compreender os recursos utilizados atualmente para atendimento pré hospitalar, dentre eles, o serviço de remoção aeromédico.

O transporte de paciente por via área segue normas e legislações específicas, exige habilitação mínima e capacitação em emergência pré-hospitalar. O transporte é feito pelo serviço de regulação responsável pelo paciente em aeronaves de asa fixa

\footnotetext{
${ }^{1}$ Enfermeira. Doutoranda em Ciências da Saúde (UFG). Universidade Federal de Goiás (Docente). Rio Verde (GO), Brasil. E-mail: reilacampos@ufg.br

2 Enfermeiro. Especialista em Urgência e Emergência. SAMU (Responsável Técnico). Águas Lindas (GO), Brasil. E-mail: pablorandel@gmail.com

${ }^{3}$ Enfermeira. Doutoranda em Enfermagem (UFG). Universidade Federal de Goiás (Docente). Jataí (GO), Brasil. E-mail: caciaregia@gmail.com

${ }^{4}$ Enfermeiro. Especialista em Urgência e Emergência. Centro Universitário Planalto do Distrito Federal (Docente). Instituto de Educação Superior de Brasília. Brasília (DF), Brasil. E-mail: professor.albertocesar@gmail.com
} 


\section{CON

ou rotativa (CFM, 2000).

O serviço aeromédico tem como foco vencer o tempo e as barreiras geográficas de acesso, garantindo a segurança e minimização dos riscos que os mesmos estão expostos (PASSOS, IPBD e et al., 2011).

Nesse contexto, a contínua busca pela qualidade de assistência dos serviços de transporte aeromédico associada ao aumento da frequência de remoção aérea de pacientes em estado crítico, tem inspirado uma busca por profissionais qualificados e especializados para atuarem na equipe multiprofissional de bordo, a qual é constituída pelo enfermeiro de bordo, o médico de bordo e o piloto (SCUISSIATO, 2012).

Diante da atual necessidade de debate, o objetivo deste estudo é descrever a formação do enfermeiro aeroespacial a partir dos pontos de vista da legislação vigente e de estudos sobre serviço aeromédico. Para atingir esse objetivo, foi descrito sobre o serviço de resgate aéreo e discutiu-se a formação do conhecimento científico em enfermagem aeroespacial.

\section{METODOLOGIA}

Trata-se de um estudo descritivo orientado pelo referencial de serviço aeromédico. A construção do estudo compreendeu a leitura de artigos, alguns trabalhos de conclusão de curso e a discussão teórica entre os autores a partir da pergunta norteadora: Qual a formação dos enfermeiros que atuam no apoio aeromédico?

Busca de publicações sobre o tema foram realizadas na Biblioteca Virtual em Saúde (BVS), Web of Science, no Portal da Coordenação de Aperfeiçoamento de Pessoal de Nível Superior (CAPES) e na US National Library of Medicine (PubMed).

Realizou-se uma seleção dos estudos de forma não controlada em agosto de 2019, pela primeira autora, a partir do cruzamento dos descritores: Educação em Enfermagem; Resgate Aéreo; Transporte de pacientes. Leitura adicional das referências citadas no artigo também foram realizadas.

Foram incluídos estudos que apresentassem no título ou resumo o tema "serviço aeromédico", "transporte aéreo de pacientes", "enfermeiro no resgate aéreo", nos idiomas português, inglês e/ou espanhol, sem delimitação do ano de publicação. Tendo em vista os locais de residência dos autores, foram realizadas reuniões virtuais entre os pares para discussão teórica a fim de estruturar reflexões sobre a pergunta norteadora. 


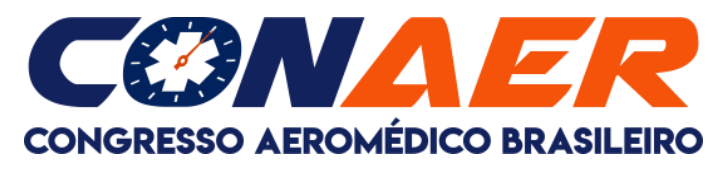

Quanto aos procedimentos éticos, não houve necessidade de submissão deste estudo ao Comitê de Ética em Pesquisa, uma vez que foram utilizadas fontes primárias publicadas em meio eletrônico para o seu desenvolvimento, bem como as experiências e opiniões dos próprios autores.

\section{RESULTADOS E DISCUSSÕES}

A partir de análise descritiva e crítica de sete publicações, sendo seis artigos e uma resolução, obtidas por meio de busca assistemática na literatura, e discussões entre os autores construiu-se duas categorias de discussão, apresentadas a seguir:

\section{Serviço de Resgate Aeromédico}

A necessidade de existir o Serviço de Resgate Aeromédico (RAM) no Brasil se dá devido à sua dimensão continental. O país apresenta extensão territorial de 8.514.876 Km2, com área correspondente a aproximadamente $1,6 \%$ de toda a superfície do planeta (CERQUEIRA, 2019).

Este estudo apresenta a diferença entre resgate aeromédico e remoção aeromédica. O resgate de acordo com Pilau (2017) é feito em aeronaves de asa rotativa e aeronaves de asa fixa. Na primeira, depende do quadro clínico que a vítima apresentar, ou seja exigir uma intervenção rápida, e as condições de trânsito tornem o transporte terrestre muito demorado. Na segunda, as condições clínicas do paciente deve ser compatível para percorrer grandes distâncias em um intervalo de tempo aceitável (PILAU, 2017).

Para as duas modalidades de transporte aeromédico de acordo com Passos et al.,(2011) é obrigatório a presença de um médico, de um piloto e de um enfermeiro a bordo. A efetividade dos voos de resgate é garantida, transportando a vítima do local do acidente até a unidade hospitalar de referência.

\section{Formação do Enfermeiro Aeroespacial}

Foi durante a Segunda Guerra Mundial que o Enfermeiro foi introduzido no transporte Aeromédico sendo chamado de Flight Nurses (BONUZZI e et al., 2016). A formação específica para o enfermeiro é ministrada pelas instituições prestadoras de assistência ao paciente aerorremovido (LUZ e et al., 2018).

Atualmente a especialidade de Enfermagem Aeroespacial é parte do cenário de resgate aeromédico de acordo com (COFEN, 2017) há alguns requisitos que 
devem ser atendidos para ingressar nesse tipo de serviço e pela Resolução 581/2018 e Resolução 610/2019, passou a definir a Enfermagem Aeroespacial como especialidade.

São exigidos do enfermeiro de acordo com Bonuzzi e et al., (2016); COFEN, (2017), uma "boa condição física, controle emocional, criatividade e habilidades de improviso para o bom desempenho durante os procedimentos de enfermagem no transporte aéreo".

A Agência Nacional de Aviação Civil (ANAC) oferece capacitação e estabelece um currículo mínimo para o treinamento da tripulação aeromédica (PASSOS et al., 2011). São considerados obrigatórios na formação do enfermeiro aeroespacial os seguintes conhecimentos:

\footnotetext{
"aspectos fisiológicos em vôo; embarque e desembarque de pacientes; segurança no interior e em torno da aeronave; instrução aos passageiros; procedimentos apropriados de emergência em vôo; de pousos de emergência e de evacuação de emergência. Estabelece ainda, um programa mínimo de formação, com curso de Medicina Aeroespacial Aplicada ao Transporte Aeromédico, com a finalidade de preparar melhor a tripulação aeromédica" (PASSOS, Isis Pienta Batista Dias; Et Al, 2011)
}

Há uma recomendação da Emergency Nurses Association e a National Flight Nurses Association, dos EUA, para que sempre haja um enfermeiro treinado na equipe de remoção aeromédica (PASSOS et al., 2011).

No Brasil, a lei $n^{\circ} 7.498 / 86$, regulamenta o Exercício do Profissional de Enfermagem e sua prática da enfermagem de bordo, e a portaria que determina a capacitação e a temática dos profissionais do transporte Aeromédico é a Portaria GM 2.048 de 5 de novembro de 2002 (BONUZZI e et al., 2016). Uma Instrução de Aviação Civil (IAC), $\mathrm{n}^{\circ}$ 3134-135-0796, sob o título Serviço de Assistência Aeromédica estabelece os requisites para os tripulantes (PASSOS, et al., 2011).

São diversas as situações que o enfermeiro aeroespacial enfrenta se comparadas ao ambiente hospitalar, é necessário considerar alguns fatores na atuação do resgate aéreo como o espaço reduzido dentro da aeronave, altitudes em relação ao solo, condições climáticas, os ruídos constantes, os estressores de vôo como vibração, umidade, ruídos, temperatura entre outros (BONUZZI e et al., 2016).

\section{CONSIDERAÇÕES FINAIS}




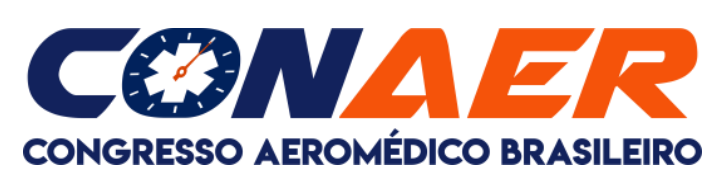

A formação do enfermeiro aeroespacial é uma área que avança e atualmente a partir da abordagem do conhecimento específico, se faz necessária nos cursos de graduação e pós graduação.

A preparação prévia é imprescindível para atuar no resgate aéreo bem como requisitos essenciais como currículo e preparação física. Assim, o Enfermeiro Aeroespacial necessita obter formação que subsidie a prestação de assistência de qualidade, de forma ágil, garantindo a segurança do paciente e da equipe no processo de resgate Aeromédico.

\section{REFERÊNCIAS}

BONUZZI, Karen Leme e colab. Revista de divulgação científica sena aires. [S.I: s.n.], 2016. v. 5. Disponível em:

<http://revistafacesa.senaaires.com.br/index.php/revisa/article/view/268>. Acesso em: 2 ago 2019.

CERQUEIRA, Wagner De. Área do Brasil - Geografia Física do Brasil. Disponível em: <https://mundoeducacao.bol.uol.com.br/geografia/area-brasil.htm>. Acesso em: 3 ago 2019.

CFM, Conselho Federal de Medicina. Departamento de Aviação Civil: Transporte aeromédico. . [S.I: s.n.]. Disponível em:

<http://www.portalmedico.org.br/pareceres/cfm/2000/14_2000.htm>. Acesso em: 2 ago 2019. , 2000

COFEN, Conselho Federal de Enfermagem. - RESOLUÇÃO COFEN No 581/2018 Normatiza a atuação do Enfermeiro no atendimento Pré-Hospitalar Móvel e Inter-Hospitalar em Aeronaves de asa fixa e rotativa. . [S.I: s.n.]. Disponível em: <http://www.cofen.gov.br/resolucao-cofen-no-05512017_52662.html>. Acesso em: 2 ago 2019. , 2017

PASSOS, Isis Pienta Batista Dias; et al. Transporte aéreo de pacientes: análise do conhecimento científico. Rev Bras Enferm, v. 64, n. 6, p. 1127-1158, 2011. Disponível em: <http://www.scielo.br/pdf/reben/v64n6/v64n6a21.pdf>. Acesso em: 3 ago 2019.

PILAU, Lorenzo. Universidade do Sul de Santa Catarina. . [S.I: s.n.], 2017. Disponível em: <https://riuni.unisul.br/bitstream/handle/12345/3091/MonografiaLORENZO PILAU.pdf?sequence=1\&isAllowed=y>. Acesso em: 2 ago 2019.

SCUISSIATO, Dayane Reinhardt et al. Revista brasileira de enfermagem.

Compreensão de enfermeiros de bordo sobre seu papel na equipe multiprofi ssional de transporte aeromédico, v. 65, n. 4, 2012. Disponível em:

<http://www.redalyc.org/articulo.oa?id=267024790010>. Acesso em: 2 ago 2019. 